\title{
ANALISIS LINGKUNGAN KERJA DAN MOTIVASI KERJA KARYAWAN CSSD-LAUNDRY, PEMELIHARAAN SARANA, DAN SANITASI RSUD dr. MOHAMAD SOEWANDHIE KOTA SURABAYA
}

\author{
Intan Agung Pratiwi Caesarianty ${ }^{*}$, Diah Wijayanti Sutha* \\ *Prodi Administrasi Rumah Sakit, \\ STIKES Yayasan RS Dr. Soetomo Surabaya, \\ Email: intancaesarianty@gmail.com
}

\begin{abstract}
ABSTRAK
Lingkungan kerja merupakan tempat dimana para karyawan melakukan aktivitas bekerja dan sangat penting untuk diperhatikan manajemen karena berpengaruh dengan motivasi kerja karyawan. Penelitian ini bertujuan untuk menganalisis kondisilingkungan kerja dan motivasi kerja karyawan instalasi cssd-laundry, instalasi pemeliharaan sarana, dan instalasi sanitasi RSUD dr. Mohamad Soewandhie Kota Surabaya.Penelitian ini merupakan penelitian deskriptif kuantitatif menggunakan analisis deskriptif dan analisis uji chi-square. Populasi dalam penelitian ini adalah seluruh karyawan instalasi CSSD-Laundry, intalasi pemeliharaan sarana, dan instalasi sanitasi RSUD dr. Mohamad Soewandhie. Pengambilan sampel dengan teknik Total Sampling dengan sampel sebesar 40 karyawan. Instrumen yang digunakan adalah kuesioner dan lembar observasi. Uji validitas dan reliabilitas instrumen dihitung dengan menggunakan aplikasi program software.Hasil penelitian menunjukkan bahwa lingkungan kerja fisik dinilai cukup baik oleh karyawan instalasi penunjang, akan tetapi karyawan di instalasi penunjang cenderung menilai tidak setuju dengan kebisingan yang ada di ruang kerja. Lingkungan kerja non fisik dinilai baik oleh karyawan instalasi penunjang dan motivasi kerja juga dinilai baik oleh karyawan instalasi penunjang. Kemudian dari hasil analisis data menunjukkan bahwa lingkungan kerja fisik berpengaruh terhadap motivasi kerja dengan ( $\mathrm{p}=0,030)$ dan lingkungan kerja non fisik berpengaruh terhadap motivasi kerja dengan $(\mathrm{p}=0,039)$. Kesimpulannya adalah lingkungan kerja fisik dan lingkungan kerja non fisik berpengaruh dan memiliki hubungan terhadap motivasi kerja. Saran yang dapat dilakukan yaitu memberikan pengaturan tata letak ruang menurut Keputusan Menteri Kesehatan Republik Indonesia Nomor 1204/MENKES/SK/X/2004 tentang Persyaratan Lingkungan Kesehatan Rumah Sakit untuk persyaratan kebisingan.
\end{abstract}

Kata kunci: Lingkungan Kerja Fisik, Lingkungan Kerja Non Fisik, Motivasi

\begin{abstract}
Work environment is a place where employees do work activities and is very important to note management because it affects the employee's motivation. This study aims to analyze the working environment and employee motivation of cssd-laundry installation, facility maintenance installation, and sanitation installation of RSUD dr. Mohamad Soewandhie Surabaya City.This research is descriptive quantitative using descriptive analysis and chisquare test analysis. Population in this research is all employees of cssd-laundry installation, facility maintenance installation, and sanitation installation of RSUD dr. Mohamad Soewandhie. Sampling with technique Total Sampling with sample of 40 employees. The instruments used were questionnaires and observation sheets. Test the validity and reliability
\end{abstract}


of the instrument is calculated by using the software program application. The results showed that physical work environment is considered respectable by the employees of the supporting installation, but the employees in the supporting installation tend to judge disagree with the noise in the work space. Non-physical work environment assessed both by supporting installation employees and work motivation is also considered great by employees of supporting facilities. Then from result of data analysis show that physical work environment have an effect on work motivation with $(p=0,030)$ and non working physical environment have an effect on work motivation with $(p=0,039)$. The conclusion is thatphysical work environment and non-physical work environment are influential and have relation to work motivation. Suggestions that can be done to provide spatial property arrangement according to Decree of Minister of Health of Republic Indonesia Number 1204 / MENKES / SK / X / 2004 about Hospital Health Environment Requirement for noise requirement.

Keywords: Physical Work Environment, Non Physical Work Environment, Work Motivation

\section{PENDAHULUAN}

Rumah Sakit Umum Daerah dr. Mohamad Soewandhie merupakan rumah sakit milik Pemerintah Kota Surabaya. RSUD dr. Mohamad Soewandhie memberikan pelayanan kesehatan pada semua bidang dan jenis penyakit, juga disertai dengan adanya sarana penunjang yang menunjang kegiatan pelayanan. Sarana penunjang yang diberikan RSUD dr. Mohamad Soewandhie yaitu padaInstalasi CSSD(Central Sterile Supply Department)-Laundry, Instalasi Pemeliharaan Sarana (IPS), dan Instalasi Sanitasi.

Berdasarkan studi pendahuluan di Instalasi CSSD-Laundry, Instalasi Pemeliharaan Sarana (IPS), dan Instalasi Sanitasi RSUD dr. Mohamad Soewandhie Kota Surabaya me-nunjukkan bahwa keadaan ruang kerja di ketiga instalasi memang kurang ideal, hal ini terlihat pada hasil observasi yaitu pada keadaan tempat kerja di Instalasi CSSD-Laundry dan
Instalasi Pemeliharaan Sarana (IPS)tidak adanya ventilasi yang cukup untuk keluar masuknya udara, sehingga menimbulkan ruangan yang pengap meskipun di ruangan telah menggunakan AC (Air Conditioner),padahal menurut Keputusan Menteri Kesehatan Republik Indonesia Nomor 1405/MENKES/SK/XI/2002 menyata-kan bahwa untuk ruangan kerja yang tidak ber-AC harus memiliki lubang ventilasi minimal $15 \%$ dari luas lantai dengan menerapkan sistem ventilasi silang dan ruang yang menggunakan AC secara periodik harus dimatikan dan diupayakan mendapat pergantian udara secara alamiah dengan cara membuka seluruh pintu dan jendela atau dengan kipas angin. Begitu juga dengan ruang kerja Instalasi Sanitasi tidak adanya ventilasi yang cukup dan kondisi ruangan yang panas menimbulkan suasana yang tidak nyaman.

Keadaan ruang kerja Instalasi Pemeliharaan Sarana (IPS) belum dipertimbangkan keselamatan kerja 
terlihat masih terdapat pipa saluran pembuangan limbah medis dan non medis di langit-langit area lingkungan kerja Instalasi Pemeliharaan Sarana (IPS) sehingga resiko kebocoran pipa saluran pembuangan limbah bisa terjadi serta kondisi ruang kerja di Instalasi Pemeliharaan Sarana (IPS) yang sesak dan tidak nyaman dilihat dari penempatan barang-barang perbaikan seperti bed pasien, kursi roda, dan lain-lain yang membuat ruangan semakin sempit. Kemudian penempatan barang-barang logistik yang bertumpuk-tumpuk dan berserakan di Instalasi Pemeliharaan Sarana yang dapat menimbulkan resiko barang jatuh dan resiko tergelincir.

Suara dari alat steril saat digunakan di Instalasi CSSD dan pada Instalasi Laundry suara bising dari mesin cuci laundry, kemudian juga pada Instalasi Pemeliharaan Sarana (IPS) suara dari mesin untuk perbaikan sarana, serta suara dari mesin IPAL di Instalasi Sanitasi dimana mesin IPAL bersebelahan dengan ruang kerja Instalasi Sanitasi yang dapat menimbulkan bahaya potensial yaitu kebisingan dimana karyawan terpapar langsung dengan bahaya kebisingan, sedangkan menurut Keputusan Menteri Kesehatan Republik Indonesia Nomor 1204/MENKES/SK/X/2004 adalah Pengaturandantataletakruanganharussede mikianrupasehingga

kamardanruanganyangmemerlukan

suasanatenangterhindardari kebisingan.

Sumber-

sumberbisingyangberasaldarirumah

sakitdansekitarnya

agardiupayakanuntukdikendalikanantarala indengancara pada sumber bising di rumah sakit: peredaman, penyekatan, pemindahan,pemeliharaanmesin-

mesinyangmenjadi sumber bising, pada sumber bising dari luar rumah sakit: penyekatan/penyerapanbisingdenganpena naman pohon(green belt),meninggikantembok,danmeninggika ntanah(bukitbuatan).

Penelitian lainnya yang dilakukan oleh Prakoso, dkk (2014) dalam jurnal dengan judul penelitian "Pengaruh Lingkungan Kerja Terhadap Motivasi Kerja dan Kinerja Karyawan (Studi Pada Karyawan PT. AXA Financial Indonesia Cabang Malang)”. Diperoleh hasil bahwa Lingkungan Kerja berpengaruh signifikan terhadap kinerja karyawan melalui motivasi kerja, yang berarti bahwa lingkungan kerja yang menyenangkan dapat memotivasi karyawan untuk bekerja lebih baik sehingga dapat meningkatkan kinerja karyawan.

Berdasarkan uraian diatas, maka penelitian ini mengambil judul Analisis Lingkungan Kerja dan Motivasi Kerja Karyawan Instalasi CSSD-Laundry, 
Instalasi Pemelihara-an Sarana (IPS), dan Instalasi Sanitasi RSUDdr. Mohamad Soewandhie Kota Surabaya Tahun 2017.

\section{METODE}

Jenis penelitian yang digunakan dalam penelitian ini adalah penelitian deskriptif kuantitatif.Berdasarkan waktu yang digunakan dalam penelitian ini yaitu dengan pendekatan cross sectional. Lokasi yang dipilih untuk dijadikan tempat penelitian adalah Rumah Sakit Umum Daerah (RSUD) dr. Mohamad Soewandhie Kota Surabaya yang terletak di Jalan Tambak Rejo 45-47 Surabaya. Penelitian ini dilakukan dalam kurun waktu 3 bulan yaitu pada bulan Mei hingga bulan Juli 2017.

Subjek penelitian dalam peneliti-an ini adalah seluruh karyawan Instalasi CSSD-Laundry, Instalasi Pemeliharaan Sarana, dan Instalasi Sanitasi yang berjumlah 40 orang. Teknik sampling dalam penelitian ini adalah non probably sampling dengan jenis total sampling yaitu seluruh populasi diambil untuk dijadikan sebagai sampel. Maka jumlah sampel dalam penelitian ini adalah 40 orang.

Instrumen yang digunakan dalam penelitian ini adalah kuesioner dan lembar observasi. Data primer didapatkan dari wawancara dan observasi. Peneliti dalam penelitian ini memperoleh data sekunder melalui penelaahan dokumen-dokumen yang terkait dengan jumlah karyawan Instalasi CSSD-Laundry, Instalasi Pemeliharaan Sarana, dan Instalasi Sanitasi, uraian tugas pokok dan fungsi (Tupoksi) karyawan, dan struktur organisasi rumah sakit.

Metode penyajian data pada penelitian ini menggunakan penyajian data dengan grafik.Teknik analisis data akan diolah dan dianalisis menggunakan program SPSS Statistiks 17.0 for windows. Analisis data yang digunakan peneliti adalah analisis deskriptif dan analisis chisquare.

Dalam penelitian ini untuk mengukur keabsahan alat instrumen kuesioner dilakukan uji validitas dan ui reliabilitas pada setiap pertanyaan yang akan digunakan dalam penelitian.

\section{HASIL}

Untuk hasil dari analisis karakteristik responden ditunjukkan pada tabel be 


\begin{tabular}{|c|c|c|c|}
\hline Karakteristik & Indikator & $\mathbf{n}$ & $\%$ \\
\hline \multirow[b]{2}{*}{ Jenis Kelamin } & Laki-laki & 31 & 77,5 \\
\hline & Perempuan & 9 & 22,5 \\
\hline \multirow{3}{*}{ Umur } & 20-35 tahun & 30 & 75 \\
\hline & 35-46 tahun & 7 & 17,5 \\
\hline & 47-60 tahun & 3 & 7,5 \\
\hline \multirow{4}{*}{ Pendidikan Terakhir } & SMA/SMK & 28 & 70 \\
\hline & DIPLOMA & 8 & 20 \\
\hline & STRATA 1 & 3 & 7,5 \\
\hline & STRATA 2 & 1 & 2,5 \\
\hline \multirow{4}{*}{ Lama Bekerja } & 1-8 tahun & 32 & 80 \\
\hline & 9-15 tahun & 6 & 15 \\
\hline & $16-25$ tahun & 1 & 2,5 \\
\hline & $>25$ tahun & 1 & 2,5 \\
\hline \multirow{2}{*}{ Status Perkawinan } & Sudah Menikah & 32 & 80 \\
\hline & Belum Menikah & 8 & 20 \\
\hline
\end{tabular}

Tabel 1 Karakteristik Responden

Berdasarkan data yang disajikan pada tabel 1, menunjukkan bahwa responden dengan jenis kelamin laki-laki sebanyak 31 responden $(77,5 \%)$, sedangkan responden dengan jenis kelamin perempuan sebanyak 9 responden (22,5\%). Pada tabel 1 diatas terlihat bahwa mayoritas karyawan di Instalasi CSSD-Laundry, Instalasi Pemeliharaan Sarana, dan Instalasi Sanitasi adalah laki-laki.

Berdasarkan jawaban responden pada angket kuesioner terdapat 30 responden yang berusia 20-35 tahun

(75,0\%), kemudian sebanyak 7 responden berusia 35-46 tahun (17,5\%), dan sebanyak 3 responden yang berusia
47-60 tahun (7,5\%). Pada tabel 1 menunjukkan bahwa mayoritas responden pada Instalasi CSSD-Laundry, Instalasi Pemelihara-an Sarana, dan Instalasi Sanitasi berdasarkan umur, berusia 20-35 tahun.

Pada tabel 1 menunjukkan bahwa jawaban responden terdapat 28 responden yang memiliki pendidikan terakhir tingkat SMA/SMK (70,0\%), kemudian sebanyak 8 responden dengan status pendidikan terakhirnya diploma (20,0\%), sebanyak 3 responden dengan pendidikan terakhir sarjana strata 1 (7,5\%), dan 1 responden dengan status pendidikan terakhir sarjana strata 2 (2,5\%). Pada tabel distribusi karakteristik responden berdasarkan pendidikan terakhir ter-lihat bahwa 
mayoritas responden memiliki status pendidikan terakhir pada tingkat SMA/SMK.

Berdasarkan jawaban responden pada angket kuesioner dari 40 responden dengan masa kerja 1-8 tahun sebanyak 32 responden (80,0\%), kemudian 6 responden (15,0\%) dengan masa kerja 9-15 tahun, dan responden dengan masa kerja 16-25 tahun (2,5\%) dan lebih dari 25 tahun (2,5\%) masing-masing terdapat 1 responden. Pada tabel 5.7 menunjukkan bahwa mayoritas responden pada instalasi penunjang berdasarkan lama bekerja yaitu dengan masa kerja 1-8 tahun.

Berdasarkan data yang disajikan pada tabel 1, menunjukkan bahwa responden dengan status perkawinan sudah menikah sebanyak 32 responden (80,0\%), sedangkan responden dengan status perkawinan belum menikah sebanyak 8 responden (20,0\%). Pada tabel 1 diatas terlihat bahwa mayoritas karyawan di Instalasi CSSD-Laundry, Instalasi Pemelihara-an Sarana, dan Instalasi Sanitasi adalah sudah menikah.

\section{A. Lingkungan Kerja Fisik}

Pengelompokkanberdasarkan jawaban responden keseluruhan mengenai kondisi lingkungan kerja fisik akan disajikan dalam grafik berikut:

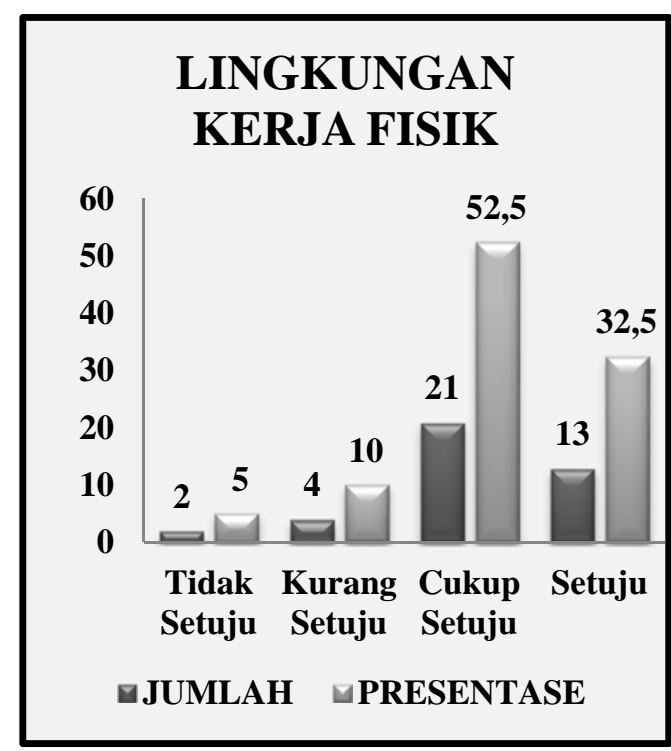

Gambar 1 Grafik Kategori Kondisi Lingkungan Kerja Fisik

Berdasarkan gambar 1 grafik kategori kondisi lingkungan kerja yang dirasakan oleh karyawan instalasi CSSD-Laundry, instalasi pemeliharaan sarana, dan instalasi sanitasi terlihat bahwa kondisi lingkungan kerja dengan nilai paling tinggi yaitu kategori cukup setuju dengan persentase sebesar 52,5\% dibandingkan dengan kategori tidak setuju sebesar 5\%, kategori kurag setuju 10\%, dan kategori setuju dengan persentase sebesar 32,5\%. 
kondisi motivasi kerja akan disajikan dalam grafik berikut:

\section{B. Lingkungan Kerja Non Fisik}

Pengelompokkan berdasarkan jawaban responden keseluruhan mengenai kondisi lingkungan kerja non fisik akan disajikan dalam grafik berikut:

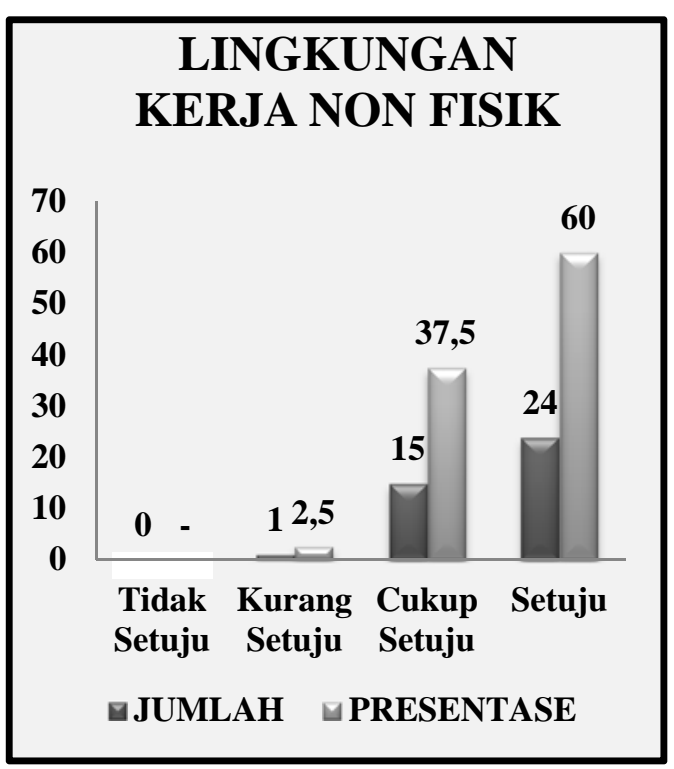

Gambar 2 Grafik Kategori Kondisi Lingkungan Kerja Non Fisik

Berdasarkan gambar 2 grafik diatas terlihat bahwa kondisi lingkungan kerja non fisik dengan nilai paling tinggi yaitu kategori setuju dengan persentase sebesar 60\% dibandingkan dengan kategori cukup setuju sebesar $37,5 \%$, kategori tidak setuju dengan persentase sebesar 2,5\%, dan untuk kategori tidak setuju mendapatkan $0 \%$.

\section{Motivasi Kerja}

Pengelompokkan berdasarkan jawaban responden keseluruhan mengenai

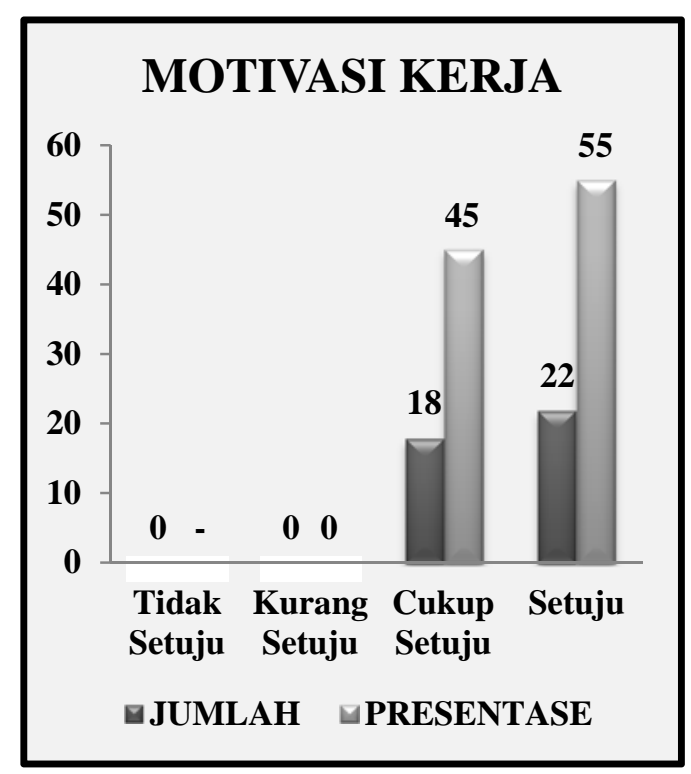

Gambar 3 Grafik Kategori Motivasi Kerja

Berdasarkan gambar 3 grafik kategori motivasi kerja yang dirasakan oleh karyawan instalasi CSSD-Laundry, instalasi pemelihara-an sarana, dan instalasi sanitasi terlihat bahwa motivasi kerja yang mereka dapatkan dengan nilai paling tinggi yaitu kategori setuju dengan persentase sebesar 55\% dibandingkan dengan kategori cukup setuju sebesar 45\%, kategori tidak setuju dengan persentase sebesar $0 \%$, dan untuk kategori tidak setuju mendapatkan $0 \%$.

\section{Analisis Chi Square}

Tabel 6. Analisis Uji Chi-Square Lingkungan Kerja Fisik dan Motivasi Kerja

Variabel Motivasi Kerja


Sig.

\begin{tabular}{l}
\hline Lingkungan Kerja \\
Fisik
\end{tabular}

Berdasarkan tabel 6 diatas terlihat bahwa lingkungan kerja fisik memiliki nilai probabilitas (Asymp Sig.) sebesar 0.030. Dasar pengambilan keputusan-nya adalah jika probabilitas $>0.05$ maka $\mathrm{H}_{0}$ diterima. Jika probabilitas $<0.05$ maka $\mathrm{H}_{0}$ ditolak.

Dari tabel 6 menunjukkan nilai probabilitas dengan Asymp. Sig-nya adalah 0.030 yang berarti lebih kecil dari 0.05, maka $\mathrm{H}_{0}$ ditolak. Hal ini menunjukkan ada hubungan antara lingkungan kerja fisik dan motivasi kerja karyawan Instalasi CSSD-Laundry, Instalasi Pemelihara-an Sarana, dan Instalasi RSUD dr. Mohamad Soewandhie Kota Surabaya.

Tabel 7 Analisis Uji Chi-Square Lingkungan Kerja Non Fisik dan Motivasi Kerja

\begin{tabular}{ccc}
\hline Variabel & \multicolumn{2}{c}{ Motivasi Kerja } \\
\cline { 2 - 3 } & \multicolumn{2}{c}{ Sig. } \\
\hline $\begin{array}{c}\text { Lingkungan } \\
\text { Kerja Non } \\
\text { Fisik }\end{array}$ & 0.039 \\
\hline
\end{tabular}

Berdasarkan tabel 7 diatas terlihat bahwa lingkungan kerja fisik memiliki nilai probabilitas (Asymp Sig.) sebesar 0.039. Dasar pengambilan keputusan-nya adalah jika probabilitas $>0.05$ maka $\mathrm{H}_{0}$ diterima. Jika probabilitas $<0.05$ maka $\mathrm{H}_{0}$ ditolak.

Dari tabel 7 menunjukkan nilai probabilitas dengan Asymp. Sig-nya adalah 0.039 yang berarti lebih kecil dari 0.05, maka $\mathrm{H}_{0}$ ditolak. Hal ini menunjukkan bahwa ada hubungan antara lingkungan kerja non fisik dan motivasi kerja karyawan Instalasi CSSD-Laundry, Instalasi Pemelihara-an Sarana, dan Instalasi RSUD dr. Mohamad Soewandhie Kota Surabaya.

\section{PEMBAHASAN}

\section{A. Karakteristik Responden dan Motivasi Kerja}

Hasil penelitian menunjukkan bahwa karyawan di ketiga instalasi, karyawan laki-laki lebih banyak dibandingkan dengan perempuan dengan persentase sebesar 77,5\% dengan 31 responden lakilaki.

Hal tersebut menunjukkan bahwa pekerjaan di ketiga instalasi tersebut cenderung membutuhkan pekerjaan lakilaki, karena seperti di instalasi pemeliharaan sarana untuk perbaikan sarana prasarana yang digunakan untuk pelayanan laki-laki lebih memiliki keahlian akan hal tersebut.

Tidak ada perbedaan jenis kelamin antara laki-laki dan perempuan terkait pekerjaan dan sama-sama memerlukan motivasi dalam bekerja, jadi tidak ada 
pembeda antara perempuan dan laki-laki. Hal tersebut didukung dengan penelitian yang dilakukan oleh Puspitasari (2006) dengan judul "Hubungan Karakteristik Biografis Karyawan dan Iklim Organisasi dengan Motivasi Kerja Karyawan PT. PLN (Persero) AJP Bogor” yang menyatakan bahwa karyawan wanita dan laki-laki mempunyai kinerja yang sama.

Pada penelitian ini ditemukan rata-rata karyawan termasuk usia produktif, yaitu 20-35 tahun dengan persentase sebesar 75\% yaitu 30 responden. Nitisemito (2009) me-nyatakan bahwa pegawai yang lebih muda cenderung mempunyai fisik yang kuat, sehingga diharapkan dapat bekerja keras dan pada umumnya mereka belum berkeluarga atau bila sudah berkeluarga anaknya relatif masih sedikit.

Tetapi pegawai yang lebih muda umumnya kurang berdisiplin, kurang bertanggungjawab dan sering berpindahpindah pekerjaan di-bandingkan pegawai yang lebih tua. Karyawan yang termasuk usia produktif merupakan faktor keunggulan yang dapat dikembangkan.

Oleh karena itu, usia produktif merupakan masa yang efektif bagi manajemen dan pimpinan di RSUD dr. Mohamad Soewandhie Kota Surabaya untuk terus mendorong, memotivasi, dan memberi kesempatan kepada karyawannya agar memiliki keinginan kuat untuk terus mengembangkan diri. Hal tersebut juga didukung dengan pernyataan dari Potter \& Perry (2006) pertumbuhan dan perkembangan usia produktif ditandai oleh: 1) per-kembangan gaya hidup personal yang meningkat; 2) kemampuan membina hubungan dengan orang lain; 3) terdapatnya komitmen yang tinggi dan memiliki kompetensi; 4) seorang berusaha mencapai dan menguasai dunia, kebiasaan berpikir rasional meningkat; 5) membuat keputusan tentang karir, pernikahan, serta peran sebagai orang tua; 6) memperoleh pengalaman hidup, pendidikan, dan kesempatan dalam pekerjaan meningkat.

Hasil penelitian ini menemukan sebagian besar tingkat pendidikan responden yaitu SMA/SMK dengan persentase sebesar $70 \%$ sebanyak 28 responden. Hal ini menunjukkan bahwa karyawan dengan tingkat pendidikan SMA/SMK memiliki pengalaman yang sesuai dengan bidang di Instalasi CSSDLaundry, Instalasi Pemeliharaan Sarana, dan Instalasi Sanitasi.

Penelitian ini mendapatkan hasil dari karakteristik individu masa kerja 1-8 tahun dengan 32 responden persentase $80 \%$. Dengan hasil yang didapatkan dari penelitian ini menunjukkan bahwa karyawan masih belum memiliki komitmen yang cukup terhadap pekerjaannya karena masa kerja yang relatif masih pendek. Padahal menurut Robbins (2003) yang mengemukakan 
bahwa semakin lama karyawan bekerja pada suatu organisasi semakin memberi dia peluang untuk menerima tugas-tugas yang lebih menantang, otonomi yang lebih besar, keleluasaan bekerja, tingkat imbalan ekstrinsik yang lebih tinggi dan peluang menduduki jabatan atau posisi yang lebih tinggi.

Selain itu Kreitner dan Kinicki (2003) juga menyatakan bahwa masa kerja yang lama akan cenderung membuat seorang pegawai betah dalam organisasi, hal ini disebabkan karena telah beradaptasi dengan lingkungan-nya yang cukup lama sehingga pegawai akan merasa nyaman dengan pekerjaannya.

Hasil penelitian mengenai karakteristik individu status per-kawinan didapatkan hasil jumlah karyawan yang sudah menikah lebih besar daripada jumlah karyawan yang belum menikah dengan total persentase sebesar $80 \%$. Hal tersebut menunjukkan bahwa dengan status sudah menikah akan merasa lebih puas dengan pekerjaan yang dilakukan. Pernyataan diatas didukung dengan temuan Robbins (2001) bahwa status perkawinan menikah merasa lebih puas dengan pekerjaannya dibanding dengan rekan kerjanya yang belum menikah.

\section{B. Lingkungan Kerja Fisik dan Motivasi Kerja}

Berdasarkan analisis hasil penelitian adapun lingkungan kerja fisik di Instalasi
CSSD-Laundry, Instalasi Pemeliharaan Sarana, dan Instalasi Sanitasi RSUD dr. Mohamad Soewandhie Kota Surabaya adalah setuju dengan keadaan lingkungan kerja fisik yang ada dengan jumlah sekitar 32,5\% menilaisetuju. Akan tetapi terdapat 52,5\% responden yang menilai lingkungan kerja fisik mereka dengan kriteria cukup setuju. Kemudian dengan responden sebesar 10\% menilai lingkungan kerja fisik mereka dengan kriteria kurang setuju dan sebesar 5\% responden menilai lingkungan kerja fisik mereka dengan kriteria tidak setuju.

Hal tersebut menunjukkan bahwa keseluruhan penilaian responden ter-hadap lingkungan kerja fisik di ketiga instalasi adalah cukup setuju, akan tetapi terdapat pernyataan dari variabel lingkungan kerja pada lembar kuesioner dimana responden cenderung menjawab tidak setuju dengan pernyataan lingkungan kerja tenang dari suara bising mesin dan lingkungan kerja tenang dari kebisingan suara lalu lalang kendaraan.

Pernyataan tersebut didukung dengan keterangan dari responden bahwa kebisingan di tempat kerja mereka dinyatakan sangat bising dan peneliti juga mengukur kebisingan dengan alat kebisingan sound level meter pada instalasi CSSD-Laundry, instalasi pemeliharaan sarana, dan instalasi sanitasi. Dimana kebisingan di instalasi CSSD- 
Laundry sebesar 65,03 dB, kemudian pada instalasi pemeliharaan sarana sebesar 56,57 dB, dan untuk instalasi sanitasi sebesar $68,23 \mathrm{~dB}$.

Menurut Keputusan Menteri Kesehatan Republik Indonesia Nomor 1204/MENKES/SK/X/2004 tentang Persyaratan Lingkungan Kesehatan Rumah Sakit untuk persyaratan kebisingan kantor dan ruang alat/gudang sebesar $45 \mathrm{~dB}$ dan untuk ruang cuci sebesar $78 \mathrm{~dB}$. Oleh karena itu kebisingan di Instalasi Pemeliharaan Sarana dan Instalasi Sanitasi belum sesuai dengan persyaratan yang ada yaitu sebesar $45 \mathrm{~dB}$, sedangkan untuk persyaratan kebisingan pada ruang cuci di Instalasi CSSD-Laundry sudah sesuai dengan persyaratan yang ada yaitu $78 \mathrm{~dB}$.

Hasil analisis data juga me-nunjukkan bahwa lingkungan kerja fisik berpengaruh dengan motivasi kerja karyawan instalasi cssd-laundry, instalasi pemeliharaan sarana, dan instalasi sanitasi RSUD dr. Mohamad Soewandhie Kota Surabaya. Penelitian lainnya yang dilakukan oleh Fahmi et al (2015) dalam artikel ilmiah mahasiswa dengan judul penelitian "Pengaruh Komunikasi dan Lingkungan Kerja terhadap Motivasi serta Kinerja Karyawan PT. PLN (Persero) Area Situbondo”. Diperoleh hasil bahwa komunikasi dan lingkungan kerja berpengaruh langsung dan tidak langsung terhadap kinerja karyawan melalui motivasi dengan arah positif.

\section{Lingkungan Kerja Non Fisik dan Motivasi Kerja}

Berdasarkan analisis hasil penelitian adapun lingkungan kerja non fisik di Instalasi CSSD-Laundry, Instalasi Pemeliharaan Sarana, dan Instalasi Sanitasi RSUD dr. Mohamad Soewandhie Kota Surabaya adalah setuju dengan keadaan lingkungan kerja non fisik yang ada dengan jumlah sekitar $60 \%$.

Akan tetapi terdapat 37,5\% responden yang menilai lingkungan kerja non fisik mereka dengan kriteria cukup setuju. Kemudian dengan responden sebesar 2.5\% menilai lingkungan kerja non fisik mereka dengan kriteria kurang setuju dan tidak ada responden yang menilai lingkungan kerja non fisik mereka dengan kriteria tidak setuju.

Hal tersebut menunjukkan bahwa keseluruhan penilaian responden terhadap lingkungan kerja non fisik di ketiga instalasi adalah setuju. Dengan kata lain karyawan instalasi cssd-laundry, instalasi pemeliharaan sarana, dan instalasi sanitasi RSUD dr. Mohamad Soewandhie merasa nyaman dengan kondisi lingkungan kerja non fisik yang mereka rasakan yaitu hubungan antara atasan dan bawahan, kemudian hubungan antara teman kerja sehingga dapat kinerja karyawan tidak 
terganggu dan dapat memotivasi karyawan untuk bekerja lebih giat.

Dari hasil analisis yang telah dilakukan menunjukkan bahwa lingkungan kerja non fisik dan motivasi kerja karyawan instalasi cssd-laundry, instalasi pemeliharaan sarana, dan instalasi sanitasi berpengaruh. Hal tersebut dinyatakan pada penelitian yang dilakukan oleh Benny et al dengan judul penelitian "Pengaruh Lingkungan Kerja Fisik dan Non Fisik terhadap Motivasi Kerja dan Kinerja Karyawan (Studi pada Karyawan PT. Bank BRI, Tbk. Cabang Bogor)” menyatakan bahwa variabel lingkungan kerja non fisik berpengaruh positif dan signifikan terhadap motivasi kerja karyawan ini dibuktikan dengan tingkat pengaruh yang berarti ada pengaruh yang signifikan.

\section{SIMPULAN}

Berdasarkan hasil analisis yang dilakukan pada penelitian ini diperoleh hasil kesimpulan sebagai berikut:

Lingkungan kerja fisik secara keseluruhan dinilai cukup baik oleh karyawan instalasi CSSD-Laundry, instalasi pemeliharaan sarana, dan instalasi sanitasi RSUD dr. Mohammad Soewandhie Kota Surabaya. Akan tetapi karyawan pada ketiga instalasi cenderung menilai tidak setuju dengan kebisingan yang ada di ruang kerja. Ada hubungan atau pegaruh yang signifikan antara lingkungan kerja fisik dengan motivasi kerja karyawan.

Lingkungan kerja non fisik secara keseluruhan dinilai baik oleh karyawan instalasi CSSD-Laundry, instalasi pemeliharaan sarana, dan instalasi sanitasi RSUD dr. Mohammad Soewandhie Kota Surabaya dan ada hubungan yang signifikan antara lingkungan kerja non fisik dengan motivasi kerja karyawan.

Motivasi kerja yang dirasakan oleh karyawan instalasi CSSD-Laundry, instalasi pemeliharaan sarana, dan instalasi sanitasi RSUD dr. Mohammad Soewandhie Kota Surabaya secara keseluruhan dinilai baik.

\section{SARAN}

Berikut beberapa saran yang dapat diajukan dalam penelitian ini antara lain:

RSUD dr. Mohamad Soewandhie perlu memperhatikan lingkungan kerja fisik terutama kebisingan yang ada di ruang kerja terutama pada instalasi-instalasi dengan resiko kebisingan yang tinggi Dengan memberikan pengaturan tata letak ruang harus sedemikian rupa agar tidak menimbulkan kebisingan dan sumber bising dapat dikendalikan dengan meredam, menyekat, pemindahan, pemeliharaan, penanaman pohon, dll sesuai dengan Keputusan Menteri Kesehatan Republik 
Indonesia

Nomor

1204/MENKES/SK/X/2004 tentang

Persyaratan Kesehatan Lingkungan

Rumah Sakit.

RSUD dr. Mohamad Soewandhie menjaga kondisi lingkungan kerja non fisik karyawan agar tetap stabil. Hal ini dapat dilakukan terus menerus dengan menjaga hubungan baik sesama karyawan dan hubungan dengan atasan, dimana akan berpengaruh pada meningkatnya motivasi dan kinerja karyawan.

RSUD dr. Mohamad Soewandhie perlu menjaga tingkat motivasi kerja karyawan agar tetap stabil. Hal ini dapat dilakukan terus menerus dengan memberikan semangat kerja bagi karyawan, sehingga dapat meningkatkan motivasi kerja karyawan. Penelitian ini dapat diajukan sebagai bahan pertimbangan untuk pengambilan keputusan.

\section{DAFTAR PUSTAKA}

Benny, S., Utami, H. N., \& Nurtjahjono, G. E. (2015). Pengaruh Lingkungan Kerja Fisik dan Non Fisik Terhadap Motivasi Kerja dan Kinerja Karyawan (Studi Pada Karyawan PT. Bank BRI, Tbk. Cabang Bogor). Jurnal Administrasi Bisnis (JAB) Vol. 21 No. 1.

Fahmi, K. M., Nuhardjo, B., \& Prajitiasari, E. D. (2015). Pengaruh Komunikasi dan Lingkungan Kerja
Terhadap Motivasi serta Kinerja Karyawan PT. PLN (Persero) Area Situbondo. Artikel Ilmiah Mahasiswa.

Keputusan Menteri Republik Indonesia Nomor 1204/MENKES/SK/X/2004 tentang Persyaratan Kesehatan Lingkungan Rumah Sakit.

Keputusan Menteri Kesehatan Nomor 1405/MENKES/SK/XI/2002 tentang Persyaratan Kesehatan Lingkungan Kerja Perkantoran dan Industri.

Nitisemito, A. S. (2009). Manajemen Personalia edisi revisi. Ghalia Indonesia.

Potter, P., \& Perry, A. (2006). Buku Ajar Fundamental: Konsep, Proses, dan Praktik. Jakarta: EGC.

Prakoso, R. D., \& al, e. (2014). Pengaruh Lingkungan Kerja terhadap Motivasi Kerja dan Kinerja Karyawan. Jurnal Administrasi Bisnis (JAB) Vol 14 No 2.

Puspitasari, R. (2006). Hubungan Karakteristik Biografis Karyawan dan Iklim Organisasi dengan Motivasi Kerja Karyawan PT. PLN (Persero) AJP Bogor. Skripsi. Bogor

Robbins, S. P. (2001). Organizational Behavior 9th Edition. Prentice Hall International Inc.

Robbins, S. P. (2003). Perilaku Organisasi Jilid 2. Jakarta: PT. Indeks Kelompok Gramedia.

Sutrisno, E. (2012). Manajemen Sumber Daya Manusia. Jakarta: Kencana. 